\title{
Effects of combined sunitinib and extracranial stereotactic radiotherapy on bone marrow hematopoiesis
}

\author{
JOHNNY KAO $^{1,2}$, JONATHAN TIMMINS ${ }^{1}$, JUNKO OZAO-CHOY ${ }^{3}$ and STUART PACKER ${ }^{4}$ \\ ${ }^{1}$ Department of Radiation Oncology, Good Samaritan Hospital Medical Center, West Islip, NY 11795; \\ ${ }^{2}$ Department of Radiation Oncology, Mount Sinai School of Medicine, New York, NY 10029; \\ ${ }^{3}$ Department of Surgery, University of California, Los Angeles (UCLA) Medical Center, Los Angeles, CA 90502; \\ ${ }^{4}$ Division of Medical Oncology, Mount Sinai School of Medicine, New York, NY 10029, USA
}

Received September 2, 2015; Accepted June 2, 2016

DOI: $10.3892 / 01.2016 .4851$

\begin{abstract}
There is considerable interest in deploying stereotactic body radiotherapy in combination with immune therapy for patients with extracranial oligometastases. In addition to angiogenesis inhibition, sunitinib appears to mediate antitumor immunity through effects on circulating monocytic cells. The current study investigated the effects of combined sunitinib and stereotactic radiotherapy on hematopoiesis. As part of a phase I/II clinical trial utilizing concurrent sunitinib (25-50 $\mathrm{mg}$ on days 1-28) and image-guided radiation therapy (40-50 Gy in 10 fractions starting on days 8-19) for patients with metastatic cancer, the complete blood count, platelet count and automatic differential were performed pretreatment and on days 8 and 19. On average, sunitinib monotherapy for 7 days resulted in a $33 \%$ decrease in monocytes and an $18 \%$ decrease in neutrophils ( $\mathrm{P}<0.01$ for all). Compared to sunitinib alone, combined sunitinib and radiation resulted in a further decrease in neutrophils, lymphocytes and platelets $(\mathrm{P}<0.05)$. Following sunitinib and radiation treatment, a greater than average decrease in monocytes $(\geq 200 / \mu 1)$ was associated with a significant increase in progression-free and overall survival times. This exploratory study provides further evidence that monocytes represent a potential biomarker in patients with solid tumors treated with sunitinib.
\end{abstract}

\section{Introduction}

While stereotactic body radiotherapy (SBRT) can effectively eradicate oligometastases, the majority of patients with distant metastases ultimately succumb to distant metastases (1). There is growing enthusiasm for combining SBRT with agents that

Correspondence to: Dr Johnny Kao, Department of Radiation Oncology, Good Samaritan Hospital Medical Center, 1000 Montauk Highway, West Islip, NY 11795, USA

E-mail: johnny.kao@chsli.org

Key words: stereotactic radiotherapy, sunitinib, hematopoiesis, monocytes, tumor immunology enhance antitumor immunity as an approach to reducing the probability of subsequent distant metastases (2,3). Ongoing studies are investigating the combination of cytotoxic Tlymphocyte-associated protein 4 (CTLA-4) and programmed cell death protein 1 (PD-1) inhibitors with radiation, particularly in melanoma (4).

Prior to the clinical development of CTLA-4 and PD-1 inhibitors, sunitinib was demonstrated to modulate the tumor microenvironment and reverse the immune suppressive function of myeloid-derived suppressor cells (MDSCs) (5). Compared with other tyrosine kinases approved for human use, sunitinib is a relatively broad spectrum tyrosine kinase inhibitor (6). Sunitinib is a selective inhibitor of multiple protein tyrosine kinases, including vascular endothelial growth factor (VEGF) receptor types 1-3, platelet-derived growth factor receptor $\alpha$ and $\beta$, c-kit, Fms-like tyrosine kinase 3, RET and colony-stimulating factor 1 receptor (7). Sunitinib reverses tumor-mediated immune suppression from human MDSCs (8). Preclinical data suggests a supra-additive antitumor effect when combining sunitinib with radiotherapy compared to either treatment independently (9).

Based on these promising data, our group conducted a clinical trial administering sunitinib followed by combined sunitinib and radiation for patients with limited metastatic cancer $(10,11)$. With long-term follow-up, this regimen achieved a 4-year progression-free survival rate of $34 \%$ (12). As part of this clinical study, an increased incidence of grades 3 and 4 myelosuppression was observed with sunitinib and radiation compared to historical controls treated with sunitinib alone (11). Comprehensive flow cytometric analysis demonstrated that sunitinib reduced the population of $\mathrm{CD} 33^{+} \mathrm{CD} 14^{+} \mathrm{CD} 16^{+}$monocytic MDSCs in patients receiving sunitinib and radiotherapy (13). To complement these studies, the current analysis was undertaken to characterize the effects of combined sunitinib and radiation therapy on hematopoiesis.

\section{Materials and methods}

Experimental therapy. The study population consisted of 21 patients with oligometastatic cancer (1-5 sites of metastatic cancer measuring $\leq 6 \mathrm{~cm}$ ) from various primary tumors enrolled on a phase I/II trial of sunitinib and radiotherapy 
Table I. Baseline characteristics of the study population $(n=21)$.

\begin{tabular}{|c|c|c|c|}
\hline Variable & Radiotherapy alone & Radiotherapy + sunitinib & P-value \\
\hline \multicolumn{4}{|l|}{ Age, years } \\
\hline Median (range) & $66(28-90)$ & $65(47-82)$ & 0.33 \\
\hline$<40, \mathrm{n}$ & 2 & 0 & \\
\hline $40-69, \mathrm{n}$ & 12 & 13 & \\
\hline$\geq 70, \mathrm{n}$ & 7 & 8 & \\
\hline Performance status, $\mathrm{n}$ & & & 0.10 \\
\hline $0-1$ & 11 & 16 & \\
\hline $2-3$ & 10 & 5 & \\
\hline Bone metastases, $\mathrm{n}$ & & & 0.58 \\
\hline Yes & 13 & 11 & \\
\hline No & 8 & 10 & \\
\hline \multicolumn{4}{|c|}{$\begin{array}{l}\text { Volume of bone marrow irradiated, } \\
\mathrm{cm}^{3} ; \text { median (range) }\end{array}$} \\
\hline Volume receiving $10 \mathrm{~Gy}$ & $59(3-220)$ & $35(1-149)$ & 0.66 \\
\hline Volume receiving $15 \mathrm{~Gy}$ & $52(3-201)$ & $29(1-114)$ & 0.16 \\
\hline Volume receiving $20 \mathrm{~Gy}$ & $40(2-191)$ & $23(0-88)$ & 0.04 \\
\hline Volume receiving $30 \mathrm{~Gy}$ & $29(0-168)$ & $11(0-74)$ & 0.04 \\
\hline Prior radiotherapy, $\mathrm{n}$ & & & 0.33 \\
\hline Yes & 7 & 11 & \\
\hline No & 14 & 10 & \\
\hline Prior chemotherapy, $\mathrm{n}$ & & & 0.72 \\
\hline Yes & 11 & 12 & \\
\hline No & 10 & 9 & \\
\hline Sites irradiated, $\mathrm{n}$ & & & 0.54 \\
\hline Bone & 11 & 13 & \\
\hline Lung & 3 & 3 & \\
\hline Liver & 2 & 4 & \\
\hline Visceral & 3 & 1 & \\
\hline Lymph node & 2 & 2 & \\
\hline Adrenal & 0 & 1 & \\
\hline
\end{tabular}

between May 2007 and September 2010 with clinical follow-up through July 2012 (NCT00463060). The institutional review board of Mount Sinai School of Medicine (New York, NY, USA) approved this study and all participants provided written informed consent. For all patients, chemotherapy was discontinued $\geq 21$ days prior to initiating protocol therapy. Sunitinib (25-50 mg qd) was administered on days 1-28. Radiotherapy was delivered to all clinically apparent sites of disease with a margin of 5-10 $\mathrm{mm}$ using an image-guided technique described elsewhere (10). The radiation doses were 40 or $50 \mathrm{~Gy}$ in 10 fractions from days 8-19. Further systemic therapy consisting of either maintenance sunitinib or chemotherapy was administered starting on day 42 at the discretion of the treating medical oncologist.

Stratifying for the location and volume of bone marrow irradiated, a matched-pair cohort analysis was performed on a contemporary cohort of 21 patients with metastatic cancer who were treated with radiation alone. These patients underwent complete blood counts immediately prior to the start and following the completion of radiotherapy. Baseline patient and treatment characteristics for the two groups are described in Table I.

Hematological measurements. Complete blood count, differential and platelet count were obtained prior to treatment and on days 8 and 19. For each patient, pretreatment values served as controls for blood levels on days 8 and 19. In the control group, complete blood counts were obtained immediately prior to the start and following the completion of radiotherapy. All hematological measurements were taken at the Mount Sinai School of Medicine laboratories using the Coulter LH 750 Hematology Analyzer (Beckman Coulter, Inc., Brea, CA, USA), which generates a five-part differential using flow cytometry technology based on volumetric impedance (using direct current) and conductivity (using high frequency electromagnetic energy and laser light scatter). This methodology has been demonstrated to correlate well with manual slide review (14).

Bone marrow normalization. As patients in the clinical trial required radiation to treatment sites throughout the body, 
Table II. Effect of sunitinib, RT and combined sunitinib + RT on circulating blood cell populations using complete blood count.

\begin{tabular}{|c|c|c|c|c|}
\hline Cell type & Baseline & Sunitinib alone (day 8) & Sunitinib+RT (day 19) & RT alone (control) \\
\hline \multicolumn{5}{|l|}{ Leukocytes } \\
\hline Count, $x 10^{9} / 1$ & $6.72(5.10-8.40)$ & $5.88(4.20-7.10)$ & $4.03(2.15-6.25)$ & $6.9(4.74-8.36)$ \\
\hline P-value & - & 0.02 & $<0.01$ & 0.76 \\
\hline \multicolumn{5}{|l|}{ Hemoglobin } \\
\hline Level, g/dl & $13.2(12.2-14.2)$ & $13.9(12.5-15.5)$ & $13.2(11.9-14.6)$ & $13.0(11.4-14.2)$ \\
\hline P-value & - & $<0.01$ & 1.0 & 0.74 \\
\hline \multicolumn{5}{|l|}{ Platelets } \\
\hline Count, $\times 10^{9} / 1$ & $196.2(131.5-260.0)$ & $192.9(145.0-249.0)$ & $145.9(90.0-192.0)$ & $174.3(114.2-201.1)$ \\
\hline P-value & - & 0.71 & $<0.01$ & 0.20 \\
\hline \multicolumn{5}{|l|}{ Neutrophils } \\
\hline Count, $\times 10^{9} / 1$ & $4.91(3.40-6.30)$ & $4.01(2.55-5.55)$ & $2.99(1.45-5.05)$ & $5.60(3.67-7.64)$ \\
\hline P-value & - & $<0.01$ & $<0.01$ & 0.36 \\
\hline \multicolumn{5}{|l|}{ Monocytes } \\
\hline Count, $\times 10^{9} / 1$ & $0.50(0.35-0.60)$ & $0.35(0.25-0.40)$ & $0.31(0.20-0.40)$ & $0.48(0.39-0.54)$ \\
\hline P-value & - & $<0.01$ & $<0.01$ & 0.60 \\
\hline \multicolumn{5}{|l|}{ Lymphocytes } \\
\hline Count, $\times 10^{9} / 1$ & $1.15(0.70-1.35)$ & $1.33(0.60-1.90)$ & $0.65(0.30-0.90)$ & $0.70(0.35-0.94)$ \\
\hline P-value & - & 0.07 & $<0.01$ & $<0.01$ \\
\hline
\end{tabular}

Data are presented as mean values (interquartile range). P-values were calculated by a paired $t$-test compared to the baseline. RT, radiotherapy.

the volume of bone marrow irradiated was quantified. To standardize measurement of bone marrow, volumes were calculated using the Eclipse Treatment Planning System 8.0 (Varian Medical Systems, Inc., Palo Alto, CA, USA) using a commercially available automatic segmentation algorithm. To account for an uneven distribution of active bone marrow throughout the body, the volume of bone marrow irradiated was estimated by applying a correction factor that was derived by cross referencing volumes of bone mass against anatomically measured volumes of marrow contained within specific bones (15). Specifically, the correction factors were 1.0 for lumbosacral spine; 0.65 for thoracic spine; 0.5 for cervical spine, rib, sternum, scapula and iliac bone; and 0.3 for humerus, mandible, femoral head and femoral neck.

Statistical analysis. A two-sided paired $t$-test was used to make comparisons between pre- and post-treatment hematological measurements. Microsoft Excel was used to plot the differences in changes in blood counts over time. Progression-free survival and overall survival rates were calculated using the Kaplan-Meier method on Stata software version 13.1 (StataCorp LP, College Station, TX, USA). Univariate comparison between groups was performed using the log-rank test.

\section{Results}

Early effects of sunitinib on hematopoiesis. The primary tumor types for patients treated with sunitinib included lung (24\%), kidney (14\%), liver (14\%), head and neck squamous cell carcinoma $(14 \%)$, prostate $(14 \%)$, pancreas $(5 \%)$, breast $(5 \%)$, melanoma (5\%) and colorectal (5\%). Using pretreatment values as controls, significant changes in hematological measurements were observed within 7 days of initiating sunitinib (Fig. 1 and Table II). On average, there was a 13\% reduction in leukocytes $\left(6.72 \times 10^{9}\right.$ vs. $\left.5.88 \times 10^{9} / 1, \mathrm{P}=0.02\right)$, largely due to a $30 \%$ decrease in monocytes $\left(0.50 \times 10^{9}\right.$ vs. $\left.0.35 \times 10^{9} / 1, \mathrm{P}<0.01\right)$ and an $18 \%$ decrease neutrophils $\left(4.91 \times 10^{9}\right.$ vs. $4.01 \times 10^{9} / 1$, $\mathrm{P}<0.01)$. Sunitinib resulted in a marginal increase in mean hemoglobin levels (13.2 vs. $13.9 \mathrm{~g} / \mathrm{dl}, \mathrm{P}<0.01)$. No patients had experienced hematological toxicity of grade 3 or above after 7 days of sunitinib treatment.

Effect of radiation alone on hematopoiesis. There were no statistically significant differences in baseline blood counts when comparing the radiation alone and combined sunitinib and radiation cohorts. Following radiation therapy alone, the only detectable difference was a $39 \%$ decrease in the mean lymphocyte count compared with baseline $\left(1.15 \times 10^{9}\right.$ vs. $\left.0.70 \times 10^{9} / 1, \mathrm{P}<0.01\right)$. Grade $2-4$ lymphopenia was observed in $76 \%$ of patients; this comprised $19 \%$ with grade $2,52 \%$ with grade 3 and $5 \%$ with grade 4 .

Effect of combined sunitinib and radiation on erythroid, lymphoid and myeloid lineages. Hematological measurements on day 19 demonstrated significant changes compared to pretreatment levels (Fig. 1 and Table II). On average, there was a $40 \%$ reduction in total leukocytes $\left(6.72 \times 10^{9}\right.$ vs. $4.03 \times 10^{9} / 1$, $\mathrm{P}<0.01)$, which included a $38 \%$ decrease in monocytes $\left(0.50 \times 10^{9}\right.$ vs. $\left.0.31 \times 10^{9} / 1, \mathrm{P}<0.01\right), 43 \%$ reduction in lymphocytes $\left(1.15 \times 10^{9}\right.$ vs. $\left.0.65 \times 10^{9} / 1, \mathrm{P}<0.01\right)$ and $39 \%$ decline in neutrophils $\left(4.91 \times 10^{9}\right.$ vs. $\left.2.99 \times 10^{9} / 1, \mathrm{P}<0.01\right)$. There was also a $26 \%$ reduction in the mean platelet count $\left(196.2 \times 10^{9}\right.$ vs. $\left.145.9 \times 10^{9} / 1, \mathrm{P}=0.006\right)$. 

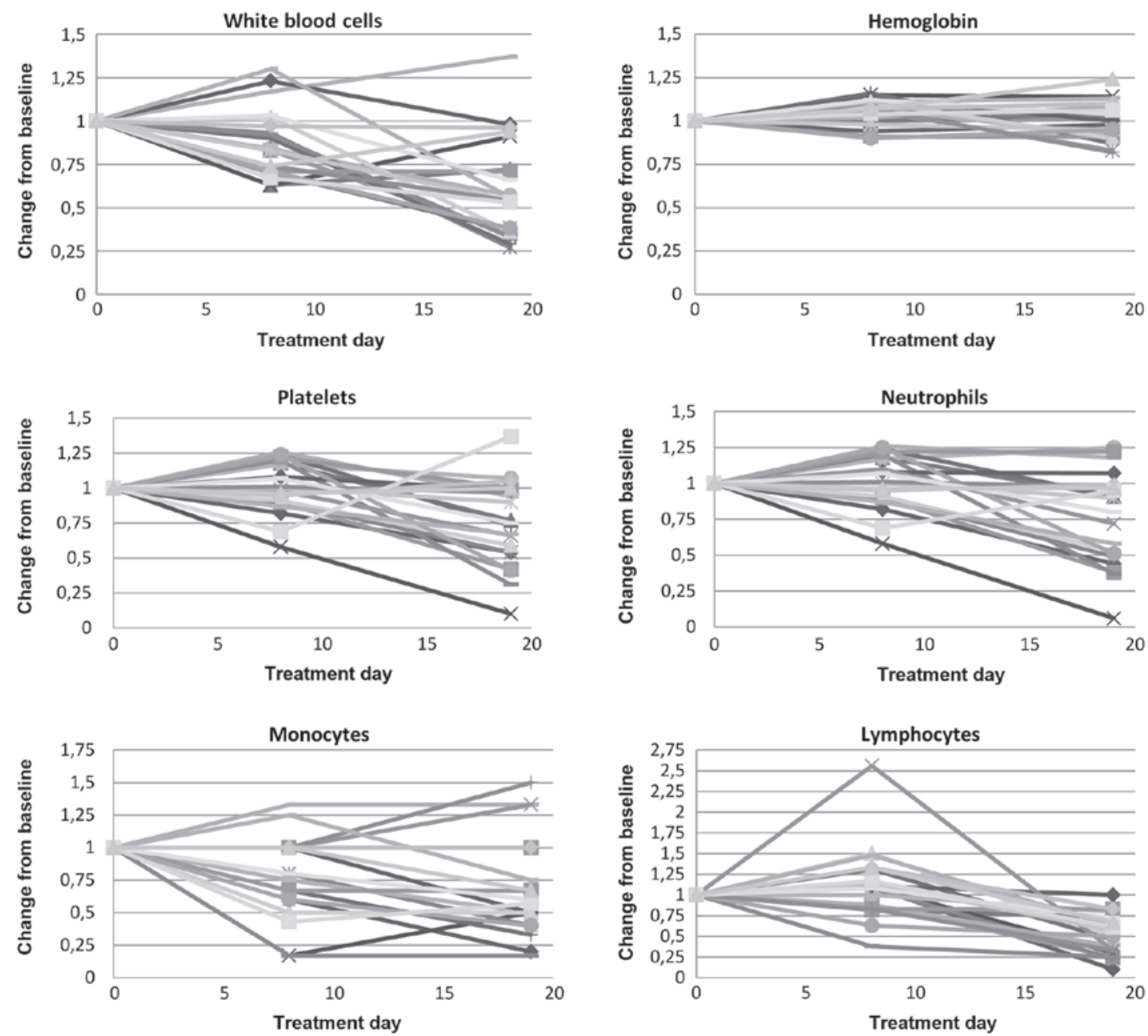

Figure 1. Effect of sunitinib and radiation on hematopoiesis in 21 patients with oligometastases. Data are presented as the percent decrease compared to baseline values.

A

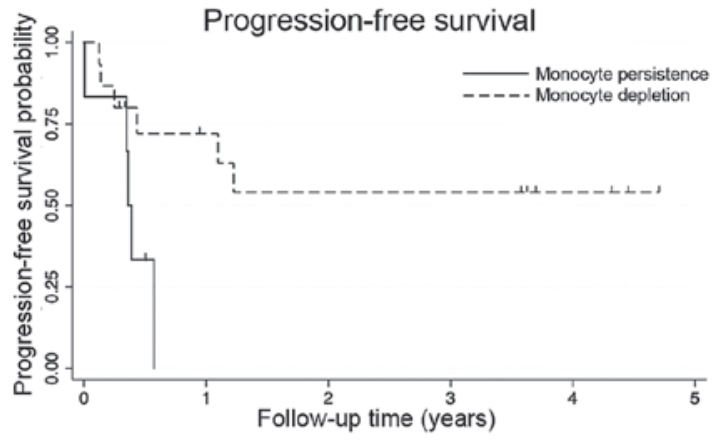

B

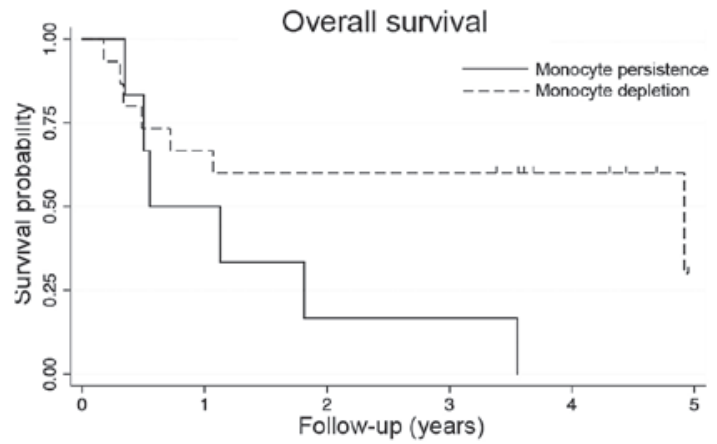

Figure 2. Kaplan-Meier analyses of (A) progression-free and (B) overall survival with monocyte depletion ( $\geq 200 / \mu$ l decrease in monocyte concentration) following sunitinib and radiation therapy.
Compared to sunitinib alone, combined sunitinib and radiation demonstrated a further decrease in mean leukocyte $(\mathrm{P}<0.01)$, platelet $(\mathrm{P}<0.01)$, neutrophil $(\mathrm{P}=0.04)$ and lymphocyte counts $(\mathrm{P}<0.01)$, but no significant change in mean hemoglobin level $(\mathrm{P}=0.07)$ or monocyte count $(\mathrm{P}=0.09)$. The incidence rates of grade 3-4 leukopenia, neutropenia, thrombocytopenia and lymphopenia were $19,5,10$ and $57 \%$, respectively.

Compared to radiation alone, patients treated with concurrent sunitinib and radiation exhibited a $40 \%$ decrease in mean leukocyte counts $(\mathrm{P}=0.01)$ and a $26 \%$ reduction in mean platelet counts $(\mathrm{P}<0.01)$. The effect on leukocytes was largely due to a $39 \%$ decline in mean neutrophil counts $(\mathrm{P}=0.03)$ and a $39 \%$ reduction in mean monocyte counts $(\mathrm{P}<0.01)$. On average, there was no effect on lymphocytes $(\mathrm{P}=0.1)$ and mild erythrocytosis $(P=0.06)$ that failed to reach statistical significance.

Potential association between outcome and decreased absolute monocyte counts following sunitinib and radiotherapy. In a recent analysis of patients with hepatocellular carcinoma treated with sunitinib, a greater decrease in monocyte count after 14 days of treatment significantly predicted progression-free and overall survival times (16). In the current study, patients with a greater than average decline $(\geq 200 / \mu l)$ in absolute monocyte count following sunitinib and 
radiation therapy had significantly improved rates of 2-year progression-free (54\% vs. 0\%, $\mathrm{P}=0.03)$ and overall survival (60\% vs. 17\%, $\mathrm{P}=0.05$ ). Progression-free and overall survival curves are shown in Fig. 2. Due to limited sample size and the hypothesis-generating nature of the analysis, multivariable analysis was not attempted.

\section{Discussion}

While conventional cytotoxic chemotherapy has been limited by a low therapeutic index, poor drug penetration through tissue, and multi-drug resistance, molecularly targeted therapies specific for a single signal transduction pathway are hindered by the genetic heterogeneity within tumors and the multiple genetic abnormalities associated with solid tumors (17-19). Broader spectrum multi-targeted tyrosine kinase inhibitors, such as sunitinib, offer a promising approach towards overcoming some of these barriers to achieving a cure, by targeting multiple pathways $(6,20)$. One clear disadvantage of relatively non-specific inhibitors is the toxicity resulting from 'off target' effects of multi-targeted agents (21). Sunitinib has been associated with decreased leukocytes, lymphocytes, hemoglobin, monocytes, platelets, neutrophils and increased median corpuscular volume (16,22-24). Clinicians are increasingly adopting more specific tyrosine kinase inhibitors that have lower rates of hematological toxicity (25).

The observed decrease in hematopoiesis following sunitinib and radiation therapy in the current study provides the clinician insight on changes in immunity. Consistent with this notion, a rapid decrease in myeloid cells following sunitinib has been associated with improved survival (16). An emerging body of research suggests that sunitinib mediates antitumor immunity through bone marrow-derived cells $(8,13)$. For instance, flow cytometric characterization of changes before and after sunitinib administration suggest that the number of immunosuppressive monocytic MDSCs and T regulatory cells decreases, while myeloid dendritic cells increase $(13,24)$.

In contrast to the immunosuppressive effects of total body radiation, recent data suggests that local tumor radiotherapy can remodel and enhance antitumor immunity (26). While wide-field radiotherapy has been demonstrated to reduce the number of neutrophils, platelets and lymphocytes, localized radiotherapy for metastases appears to selectively deplete lymphocytes (27). To the best of our knowledge, the current report is the first to evaluate the effect of a biologically targeted agent on hematopoiesis in patients receiving radiotherapy. In this study, the combination of sunitinib and radiotherapy resulted in a decrease of mean platelet, myeloid and lymphoid blood counts, with relative sparing of red blood cells. Flow cytometry demonstrated that combined sunitinib and radiation depleted monocytic MDSCs, T regulatory and B cells compared with radiation alone (13). Further studies should explore changes in plasma biomarkers contributing to these observed changes in circulating cells.

The further development of sunitinib for applications beyond renal cell carcinoma, pancreatic neuroendocrine tumors and gastrointestinal stromal tumors would be enhanced by the development of predictive biomarkers (28). Among circulating hematopoietic cells, sunitinib selectively depletes CD14-positive monocytes that co-express VEGF-1 or C-X-C chemokine receptor type 4 (29). More recent immune profiling suggests that sunitinib selectively targets $\mathrm{CD} 33^{+} \mathrm{CD} 14^{+}$ $\mathrm{CD} 6^{+}$monocytic MDSCs and $\mathrm{CD} 15^{+} \mathrm{CD} 14^{-}$neutrophilic MDSCs $(13,30)$. The present results confirm the observation that a greater reduction in monocytes following sunitinib therapy is associated with higher progression-free and overall survival times in patients with advanced malignancy (16). While further confirmatory studies are required, this could serve as an early biomarker of sunitinib efficacy.

Although the present study provides novel observations, it has numerous limitations. Firstly, the sample size was extremely limited and the patient population was highly heterogeneous. Therefore, the potential association between monocyte depletion and improved outcome should be considered as hypothesis-generating. Secondly, observations of selective effects on circulating cells in peripheral blood may not necessarily reflect biology in the tumor bed (30). Arguably, this problem may be less relevant when all areas of gross disease are ablated with surgery or radiation. Finally, the clinical relevance of combined sunitinib and radiation has decreased as interest in combining angiogenesis inhibitors with radiotherapy has waned (31). However, lessons learned from the experience of combining radiotherapy with novel agents, including sunitinib, may inform future studies combining radiotherapy with immunotherapy for advanced cancer $(4,32)$.

In conclusion, the present study reports changes in hematopoiesis following sunitinib and radiotherapy that supplement previously reported flow cytometric data.

\section{Acknowledgements}

This study was supported in part by research funding from Pfizer Inc. (New York, NY, USA) awarded to Dr Johnny Kao. Dr Johnny Kao is a William Harris Research Fellow.

\section{References}

1. Salama JK, Hasselle MD, Chmura SJ, Malik R, Mehta N, Yenice KM, Villaflor VM, Stadler WM, Hoffman PC, Cohen EE, et al: Stereotactic body radiotherapy for multisite extracranial oligometastases: Final report of a dose escalation trial in patients with 1 to 5 sites of metastatic disease. Cancer 118: 2962-2970, 2012.

2. Postow MA, Callahan MK, Barker CA, Yamada Y, Yuan J, Kitano S, Mu Z, Rasalan T, Adamow M, Ritter E, et al: Immunologic correlates of the abscopal effect in a patient with melanoma. N Engl J Med 366: 925-931, 2012.

3. Deng L, Liang H, Burnette B, Beckett M, Darga T, Weichselbaum RR and Fu YX: Irradiation and anti-PD-L1 treatment synergistically promote antitumor immunity in mice. J Clin Invest 124: 687-695, 2014.

4. Twyman-Saints Victor C, Rech AJ, Maity A, Rengan R, Pauken KE, Stelekati E, Benci JL, Xu B, Dada H, Odorizzi PM, et al: Radiation and dual checkpoint blockade activate non-redundant immune mechanisms in cancer. Nature 520: 373-377, 2015.

5. Ozao-Choy J, Ma G, Kao J, Wang GX, Meseck M, Sung M, Schwartz M, Divino CM, Pan PY and Chen SH: The novel role of tyrosine kinase inhibitor in the reversal of immune suppression and modulation of tumor microenvironment for immune-based cancer therapies. Cancer Res 69: 2514-2522, 2009.

6. Karaman MW, Herrgard S, Treiber DK, Gallant P, Atteridge CE, Campbell BT, Chan KW, Ciceri P, Davis MI, Edeen PT, et al: A quantitative analysis of kinase inhibitor selectivity. Nat Biotechnol 26: 127-132, 2008.

7. Faivre S, Demetri G, Sargent W and Raymond E: Molecular basis for sunitinib efficacy and future clinical development. Nat Rev Drug Discov 6: 734-745, 2007. 
8. Ko JS,Zea AH, Rini BI, Ireland JL,Elson P, Cohen P, Golshayan A, Rayman PA, Wood L, Garcia J, et al: Sunitinib mediates reversal of myeloid-derived suppressor cell accumulation in renal cell carcinoma patients. Clin Cancer Res 15: 2148-2157, 2009.

9. Schueneman AJ, Himmelfarb E, Geng L, Tan J, Donnelly E, Mendel D, McMahon G and Hallahan DE: SU11248 maintenance therapy prevents tumor regrowth after fractionated irradiation of murine tumor models. Cancer Res 63: 4009-4016, 2003.

10. Kao J, Packer S, Vu HL, Schwartz ME, Sung MW, Stock RG, Lo YC, Huang D, Chen SH and Cesaretti JA: Phase 1 study of concurrent sunitinib and image-guided radiotherapy followed by maintenance sunitinib for patients with oligometastases: Acute toxicity and preliminary response. Cancer 115: 3571-3580, 2009.

11. Tong CC, Ko EC, Sung MW, Cesaretti JA, Stock RG, Packer SH, Forsythe K, Genden EM, Schwartz M, Lau KH, et al: Phase II trial of concurrent sunitinib and image-guided radiotherapy for oligometastases. PLoS One 7: e36979, 2012.

12. Kao J, Chen CT, Tong CC, Packer SH, Schwartz M, Chen SH and Sung MW: Concurrent sunitinib and stereotactic body radiotherapy for patients with oligometastases: Final report of a prospective clinical trial. Target Oncol 9: 145-153, 2014.

13. Chen HM, Ma G, Gildener-Leapman N, Eisenstein S, Coakley BA, Ozao J, Mandeli J, Divino C, Schwartz M, Sung M, et al: Myeloid derived suppressor cells as an immune parameter in patients with concurrent sunitinib and stereotactic body radiotherapy. Clin Cancer Res 21: 4073-4085, 2015.

14. Chin-Yee IH, Keeney M, Johnson K, Brown W, Wolfe N and Kaplan S: White blood cell flagging rates of the Coulter LH 750 analyzer compared with the Coulter Gen.s Hematology Analyzer. Laboratory Hematology 7: 211-216, 2001.

15. Ellis RE: The distribution of active bone marrow in the adult. Phys Med Biol 5: 255-258, 1961.

16. Zhu AX, Duda DG, Ancukiewicz M, di Tomaso E, Clark JW, Miksad R, Fuchs CS, Ryan DP and Jain RK: Exploratory analysis of early toxicity of sunitinib in advanced hepatocellular carcinoma patients: Kinetics and potential biomarker value. Clin Cancer Res 17: 918-927, 2011.

17. Gonzalez-Garcia I, Solé RV and Costa J: Metapopulation dynamics and spatial heterogeneity in cancer. Proc Natl Acad Sci USA 99: 13085-13089, 2002.

18. Hanahan D and Weinberg RA: The hallmarks of cancer. Cell 100 57-70, 2000.

19. Tannock IF: Conventional cancer therapy: Promise broken or promise delayed? Lancet 351 (Suppl 2): SII9-SI16, 1998.

20. Hanahan D and Weinberg RA: Hallmarks of cancer: The next generation. Cell 144: 646-674, 2011.

21. Morabito A, De Maio E, Di Maio M, Normanno N and Perrone F: Tyrosine kinase inhibitors of vascular endothelial growth factor receptors in clinical trials: Current status and future directions. Oncologist 11: 753-764, 2006.
22. Norden-Zfoni A, Desai J, Manola J, Beaudry P, Force J, Maki R, Folkman J, Bello C, Baum C, DePrimo SE, et al: Blood-based biomarkers of SU11248 activity and clinical outcome in patients with metastatic imatinib-resistant gastrointestinal stromal tumor. Clin Cancer Res 13: 2643-2650, 2007.

23. Rini BI, Choueiri TK, Elson P, Khasawneh MK, Cotta C, Unnithan J, Wood L, Mekhail T, Garcia J, Dreicer R and Bukowski RM: Sunitinib-induced macrocytosis in patients with metastatic renal cell carcinoma. Cancer 113: 1309-1314, 2008.

24. van Cruijsen H, van der Veldt AA, Vroling L, Oosterhoff D, Broxterman HJ, Scheper RJ, Giaccone G, Haanen JB, van den Eertwegh AJ, Boven E, et al: Sunitinib-induced myeloid lineage redistribution in renal cell cancer patients: $\mathrm{CD} 1 \mathrm{c}+$ dendritic cell frequency predicts progression-free survival. Clin Cancer Res 14: 5884-5892, 2008.

25. Motzer RJ, Hutson TE, Cella D, Reeves J, Hawkins R, Guo J, Nathan P, Staehler M, de Souza P, Merchan JR, et al: Pazopanib versus sunitinib in metastatic renal-cell carcinoma. $\mathrm{N}$ Engl J Med 369: 722-731, 2013

26. Formenti SC and Demaria S: Combining radiotherapy and cancer immunotherapy: A paradigm shift. J Natl Cancer Inst 105: 256-265, 2013.

27. Mac Manus M, Lamborn K, Khan W, Varghese A, Graef L and Knox S: Radiotherapy-associated neutropenia and thrombocytopenia: Analysis of risk factors and development of a predictive model. Blood 89: 2303-2310, 1997.

28. Leighl NB: Sunitinib: The next advance in small-cell lung cancer? J Clin Oncol 33: 1637-1639, 2015.

29. Zurita AJ, Khajavi M, Wu HK, Tye L, Huang X, Kulke MH, Lenz HJ, Meropol NJ, Carley W, DePrimo SE, et al: Circulating cytokines and monocyte subpopulations as biomarkers of outcome and biological activity in sunitinib-treated patients with advanced neuroendocrine tumours. Br J Cancer 112: 1199-1205, 2015

30. Ko JS, Rayman P, Ireland J, Swaidani S, Li G, Bunting KD, Rini B, Finke JH and Cohen PA: Direct and differential suppression of myeloid-derived suppressor cell subsets by sunitinib is compartmentally constrained. Cancer Res 70: 3526-3536, 2010

31. Gilbert MR, Dignam JJ, Armstrong TS, Wefel JS, Blumenthal DT, Vogelbaum MA, Colman H, Chakravarti A, Pugh S, Won M, et al: A randomized trial of bevacizumab for newly diagnosed glioblastoma. N Engl J Med 370: 699-708, 2014.

32. Kwon ED, Drake CG, Scher HI, Fizazi K, Bossi A, van den Eertwegh AJ, Krainer M, Houede N, Santos R, Mahammedi $\mathrm{H}$, et al: Ipilimumab versus placebo after radiotherapy in patients with metastatic castration-resistant prostate cancer that had progressed after docetaxel chemotherapy (CA184-043): A multicentre, randomised, double-blind, phase 3 trial. Lancet Oncol 15: 700-712, 2014 